\title{
İkidillilik Bağlamında Kürtçeden Türkçeye Çevrilen Bazı İfadeler
}

\author{
Nurullah Aykaç ${ }^{1}$
}

Received: June 11, 2016

Reviewed: June 24, 2016

Accepted: July 22, 2016

\section{$\ddot{O} \mathbf{z}$}

Ana dili Kürtçe olup Türkçeyi sonraki yıllarda okul veya sosyal çevrede öğrenen kişilerin, kendilerini yazılı veya sözlü ifade ederken, Kürtçe dil mantığı ile düşünüp Türkçe konuşmaları sonucu ortaya çıkan ifadelerin göz önüne serildiği çalışmamızda ikidillilik sonucunda ortaya çıkan ifade çevirilerinin fark edilmesi ve eğitim öğretim sürecinde verilen dil eğitimleri ile bu tür durumlara dikkat çekilmesi amaçlanmıştır. Özellikle eğitim öğretim sürecinde kişilerin kendilerini doğru ifade edebilmeleri için bu tip ifadelerin tespiti ve düzeltilmesi önemli görülmektedir. Çalışmanın yapıldığg il ve bölgede bu ifadeler normal ve doğru olarak kabul edilse bile bahsedilen bölge dışında eğitim ve sosyal yaşantılarını devam ettiren kişiler bu ifadelerden kaynaklanan iletişim sorunları ile karşılaşabilmektedirler. $\mathrm{Bu}$ nedenle bu ifadelerin tespiti ve düzeltilmesi hem eğitim öğretim ortamlarında hem de sosyal ortamlarda kişinin kendini doğru ifade edip doğru anlaşılmasını sağlayacaktır. Bu nedenle bu ve buna benzer çalışmalar önemli görülmektedir. Kişilerin iki ayrı dile sahip olması veya iki ayrı dille okuyup yazmasını karşılayan ikidillilik bir ana dil ve bir de sonradan öğrenilen dilde oluşmaktadır. İki dilli bireylerin eğitim öğretim hayatlarında, iş ve sosyal hayatlarında kendilerini daha doğru ve rahat ifade edebilmeleri için kullandıkları iki dilin dil yapısını, kurallarını iyi bilmeleri gerekmektedir. Aksi durumda bu çalışmamızda değindiğimiz gibi bir dilden diğerine birebir çeviri yapılarak ifadeler yanlış anlamaya/anlaşılmaya sebep olacak şekilde kullanılabilmektedir. Kişilerin birinci dilden ikinci dile aktardıkları bu gibi ifadelerin düzelebilmesi verilen dil dersleri ile de ilgilidir. Ayrıca okullarda seçmeli olarak verilen Kürtçe derslerinin içeriğinin zenginleştirilmesi, ders saatlerinin arttırılması ve dersi verecek kişilerin bu alanda donanımlı kişiler olmasının da faydalı olacağı düşünülmektedir.

Anahtar kelimeler: Kürtçe, Türkçe, İkidillilik, çiftdillilik, anadil.

\section{Recommended citation:}

Aykaç N. (2016). İkidillilik Bağlamında Kürtçeden Türkçeye Çevrilen Bazı İfadeler. International Journal of Kurdish Studies 2 (3), 238 - 249.

\footnotetext{
${ }^{1}$ Okutman, Dicle Üniversitesi, El.mek: nurullah.aykac@ dicle.edu.tr
} 


\title{
Some expressions in the context of bilingualism translated From Kurdish to Turkish
}

\begin{abstract}
When people whose mother tongue are kurdish however who are learned turkish at school or social surrounding in later years Express themselves in verbal and written, in our work which is shown thinking with Kurdish logic and the resulting expression of Turkish speaking, realizing the expression translation which comes out as a result of two language and attention to this situation with education which is given in education has been aimed. The detection and correction of such statements seem important especially in teaching process for people can express themselves correctly. Even if statements are accepted as normal and correctly at provinces and regions in which the work was conducted, people who continue their education and social life outside of said region can be encountered with communication problems resulting from these statements. Therefore,detection and correction of these statements will provide people Express and understanding themselves correctly both teaching and learning environment and social environment. Therefore, these and similar studies is considered important.Bilingualism which occur to have two different language or read and write in two different languages. Bilingual individuals need to know beter the structure and rules of bilingual language which they use in the education life,work and social life for they can express themselves more comfortable and accurate. Otherwise, as mentioned in this study expressions can be used to be lead to misunderstanding and understandable making verbatim translation from one language to another. It is concerned with language courses which such expression that transfer from first language to second language. In addition to, it is thought to be useful kurdish lesson which optionally given in schools enriching the content, increasing the number of teaching hours and be equipped person in this field.
\end{abstract}

Keywords: Kurdish, Turkish, Bilingualism, Mother Tongue.

\begin{abstract}
AMAÇ
Ana dili Kürtçe olup Türkçeyi sonraki yıllarda okul veya sosyal çevrede öğrenen kişilerin, kendilerini yazılı veya sözlü ifade ederken, Kürtçe dil mantığı ile düşünüp Türkçe konuşmaları sonucu ortaya çıkan ifadelerin göz önüne serilmesi amaçlanmıştır. Böylece ikidillilik sonucunda ortaya çıkan bu tür ifade çevirilerinin fark edilmesi ve eğitim öğretim sürecinde verilen dil eğitimleri ile bu tür durumlara dikkat çekilmesi amaçlanmıştır. Özellikle eğitim öğretim sürecinde kişilerin kendilerini doğru ifade edebilmeleri için bu tip ifadelerin tespiti ve düzeltilmesi önemli görülmektedir. Çalışmanın yapıldığı il ve bölgede bu ifadeler normal ve doğru olarak kabul edilse bile bahsedilen bölge dışında eğitim ve sosyal yaşantılarını devam ettiren kişiler bu ifadelerden kaynaklanan iletişim sorunları ile karşılaşabilmektedirler. Bu nedenle bu ifadelerin tespiti ve düzeltilmesi hem eğitim öğretim ortamlarında hem de sosyal ortamlarda kişinin kendini doğru ifade edip doğru anlaşılmasını sağlayacaktır. Bu nedenle bu ve buna benzer çalışmalar önemli görülmektedir.
\end{abstract}




\section{YÖNTEM}

Kişilerin Kürtçeden Türkçeye birebir çeviri yaparak kullandığı ifadelerin belirlenmesi amaciyla ortaokulda okuyan ve ana dilleri Kürtçe olan bir grup öğrencinin, farklı konularda yazmış oldukları yazılar incelenmiştir. Bu yazılardan Kürtçeden Türkçeye birebir çeviri yolu ile geçen ifadeler ayıklanmıştır. Bu çalışmanın yanı sıra eğitim öğretim ortamlarında, sosyal yaşam alanlarında gözlemler yapılıp notlar alınmıştır. Elde edilen ifadeler yörede yaşayan kişilerin fikirleri doğrultusunda süzgeçten geçirilip değerlendirilmiştir.

\section{DİL}

İnsanların doğası gereği birçok ihtiyacı vardır. Bu ihtiyaçlar kimi araştırmacılar tarafından maddeler halinde sıralanmış kimisi de piramit şeklinde basamaklandırılmıştır. İnsanların bu zaruri ihtiyaçlarından biri de iletişimdir. İletişim kurmak için de araç olarak dilleri kullanırız. İnsanların birbirleriyle iletişim kurma ihtiyacından doğan diller aracılığıyla duygularımızı, düşüncelerimizi ifade ederiz.

Ergin, (2000:3) "Dil, insanlar arasında anlaşmayı sağlayan tabii bir vasıta, kendine mahsus kanunları olan ve ancak bu kanunlar çerçevesinde gelişen canlı bir varlık, temeli bilinmeyen zamanlarda atılmış bir gizli antlaşmalar sistemi, seslerden örülmüş içtimaî bir müessesedir."

Aksan, (1979: 98) "dil, düşünce, duygu ve isteklerin bir toplumda ses ve anlam yönünden ortak olan öğeler ve kurallardan yararlanarak başkalarına aktarılmasını sağlayan çok yönlü gelişmiş bir dizgedir"

Arat, (1966: 87) dilin "bir topluluğun ayrı ferdleri arasında anlaşmayı temin ettiğini"; Tekin (1994:91) ise bütün dil bilimcilerinin Amerikan dilcisi E.H. Sturtevant'1n dil tanımı üzerinde birleşmiş olduğunu iddia ederek, ona ait şu tanımı verir: "Dil, bir insan topluluğu bireylerinin işbirliği yapmalarını ve karşılıklı eylemde bulunmalarını sağlayan keyfi veya nedensiz bir ses işaretleri sistemidir."

Muhatabın tepkisini harekete geçirmeyi hedefleyen (Prazig, 2003: 69) ve "sözcüklerin mantıki bir diziliş içinde bir araya gelmesinden oluşmuş iletişim vasıtası" (Aktaş ve Gündüz, 2002: 8) olarak görülen dilin farklı tanımları olsa da özünde aynı anlamı ifade ettikleri düşünülmektedir.

Yapılan tanımlardan da görüleceği gibi insanın kendini ifade etmesini sağlayan dil, kelime, kelime grubu ve cümle şeklindeki ifadelerden oluşur. İster yazılı olarak ister sözlü olarak kendimizi ifade ederken kullandığımız kelime, kelime grubu ve cümlelerin doğru seçilmiş olması ve kastettiğimiz anlamı ifade ediyor olması önemlidir. Bazen aynı dili konuşan kişilerde ifade yanlışlıklarından kaynaklanan iletişim kopuklukları olabilmektedir. $\mathrm{Bu}$ nedenle konuşulan dilin yapısının bilinmesi ve yeteri kadar kelime hazinesine sahip olmak önemli görülmektedir. 


\section{ANA DİL}

İnsanlar doğumdan sonra bebeklik döneminde duydukları sesleri taklit ederek kelime öğrenmeye başlarlar. Öğrendikleri kelimeler de genellikle anne, baba, kardeş ve diğer aile fertlerinin söylediği kelimelerden oluşmaktadır. İşte çocukken kişilerin aile, çevre ve soyca bağlı olduğu topluluktan öğrendiği dil onun ana dili olarak kabul edilir.

Anadili, sözlüklerde "insanın doğup büyüdüğü aile ya da toplum içinde öğrendiği”" (Büyük Sözlük: 114), “çocuklukta, anadan, çevreden öğrenilen” (Demiray, 1998: 41), “insanın çocukken anasından, evindekilerden veya soyca bağlı olduğu topluluktan öğrendiği dil” (TDK, 1998: 104) olarak tanımlanmaktadır.

\section{İKİiLLLILİK}

İkidillilik, "iki ayrı dile sahip olma veya iki ayrı dili okuyup yazma gücünde ve becerisinde olma" (TDK, 1998: ), "bir kimsenin iki dil bilmesi; bir ülkede, iki dil ya da aynı dilin, bilim dili ve halk dili gibi ayrı biçimlerinin konuşulması" (Büyük Sözlük: 1051) şeklinde sözlüklerde yer almıştır.

Bir kişi, bir meslek, bir topluluk veya bütün bir dil toplumunda görülen iki dil kullanma durumu, iki dillilik (bilingualism, diglossia) olarak bilinir (Karaağaç, 2011: 222). $\mathrm{Bu}$ dillerden bir tanesi ana dil diğeri veya diğerleri ise aile, sosyal çevre veya eğitim sonucunda öğrenilmiş dil/diller olabilmektedir.

Temel ve Şimşek Bekir (2005: 65), dilbilimcilerin iki dillilik konusunda iki gruba ayrıldığını ifade etmişlerdir. Buna göre bir grubun iki dili de ileri düzeyde bilmesi ve iki dile de hâkim olmasını iki dillilik olarak kabul ederken, başka bir grup da az seviyedeki iki dil becerisinin iki dillilik için yeterli olabileceğini savunmaktadır. $\mathrm{Bu}$ ve buna benzer farklı tanımlamalardan da rahat bir şekilde anlaşılmaktadır ki iki dillilikte bir dilin diğer dile oranla daha baskın olması da söz konusu olabilmektedir. Yani kişi ne kadar da bildiği dillerin yapısına, dil mantığına hâkim olsa da mutlaka bir dilin baskınlı̆̆ inkar edilememektedir.

İki dilli bireylerde, kişi sahip olduğu iki dilin de sözcük dizimi özelliğini aktif tutmaktadır. Yani iki dilli kişiler her kavram için genellikle iki dile ait olan iki ayrı şekil kullansa bile bu sözcükleri aynı kavram sistemine bağlayabilmektedir. İkinci bir dilin etkisi sonucunda gelişen anlam değişmeleri hem sözcüklerde hem de ifadelerde kendini gösterebilmektedir (Boeschoten, 1998: 1). Çalışmamızda üzerinde durduğumuz şekliyle iki dilli bireyler, Türkçe dil mantığıyla Kürtçe konuşabilmekte veya Kürtçe dil mantığı ile Türkçe konuşabilmektedir. $\mathrm{Bu}$ durum bazen ifadelerin doğrudan birinci veya ikinci dile tercüme edilmesi ile de kendini gösterebilmektedir. Çavuşoğlu (akt. Aydın, 2013: 659), ilk öğrenilen dilin her zaman sonradan öğrenilen dilden baskın olduğunu ve sonradan öğrenilen dilin, birincinin yüzeysel tercümesi gibi olduğunu ifade etmiştir.

Kişilerin iki ayrı dile sahip olması veya iki ayrı dille okuyup yazmasını karşılayan ikidillilik bir ana dil ve bir de sonradan öğrenilen dilde oluşmaktadır. Eğer kişiler hem ana dilleri ile hem sonradan öğrendikleri dil ile kendilerini yazılı veya sözlü olarak doğru ifade edebiliyorlarsa ikidillilik kişiler için bir avantaja dönüşebilmektedir. Fakat iki dilden birisi ile 
kendisini daha doğru ve rahat ifade edebiliyorsa az bilinen dilde diğer dilin etkilerinin çokça varlık gösterdiği görülmektedir. Bu durum da anlama ve anlatım bakımından sorun teşkil edebilmektedir. Alpöge, eğitim öğretim aşamasında karşılaşılan problemlerin temelinde anadillerini iyi öğrenememelerinin yattığını ifade eder (Alpöge, 2014).

Milli Eğitim Bakanlığı, yeni göreve başlayan öğretmenlere rehberlik etmesi için yayımladığı "Hoş Geldin Öğretmenim” (MEB, 150-151) kitabında, öğrencilerin Türkçe konuşamama sorununun, öğretmenin görev yaptığı yerde yaşadığı en önemli problemlerden birisi olduğunu belirtmiştir. Kitapta Türkçe bilmeyen çocuklara okuma yazma öğretmenin oldukça uğraş gerektirdiği de ifade edilmiştir. Söz konusu eserde, Türkçe bilmeyen öğrencilerle karşılaşan öğretmenlerin öğrencilerin nasıl davranmaları gerektiğine, nasıl bir yol izlemeleri gerektiğine kısa birkaç cümle ile değinilmiştir. Fakat burada ifade edilen düşüncelerin uzun vadede çözüm için işe yaramadığı görülmektedir.

Kürt nüfusunun yoğun olarak yaşadığı yerlerde özellikle de köylerde çocuklar ilk dil olarak Kürtçe duyarak ve öğrenerek büyüyorlar. Fakat özellikle son zamanlarda göç, televizyon ve internet kullanımının yaygınlığı, yolculuk gibi olanakların etkisiyle ana dili Kürtçe olan çocuklar doğumla birlikte yaşantılarında iki veya daha fazla dille karşılaşabilmektedirler (Derince, 2012: 146). Bu kişiler sonradan sosyal çevre, eğitim ortamları gibi farklı kanallardan Türkçe öğrenmektedirler. Fakat sonradan öğrendikleri Türkçe ile duygu ve düşüncelerini tam olarak ifade edemeyebiliyorlar. Bu nedenle kendilerini ifade ederken ana dilde ikinci dile doğrudan çeviri yaparak bazı duygu ve düşüncelerini dile getirebilmektedirler. $\mathrm{Bu}$ durumda kendilerini ifade etmede yetersiz kalabilmektedirler. Derince (2012: 14), bu gibi durumlarda bu kişilerin bazen kendilerini yetersiz görmelerine, özgüven sorunu yaşamalarına sebep olabileceğini ifade etmiştir.

Türkel, Savaş ve Savaşçı (2014: 1013), ülkemizde ana dilleri farklı olan toplulukların varlığının ana dili öğretimi açısından göz önünde bulundurulması zorunlu bir gerçeklik olduğunu belirtmişlerdir. Ayrıca ülkemizdeki ana dili farklı olan toplulukları birleştirici bir unsur olarak Türkçe'nin ana dili farklı olan çocuklara da sağlıklı bir şekilde öğretilmesi önündeki engellerin tanınması, bunları aşmaya yönelik önlemlerin alınması açısından önemli bir gereksinim olduğunu bu açıdan başka ana dillerin yanı sıra ana dili Kürtçe olan öğrencilerin yazmaya yönelik tutumları araştırılmaya gereksinim duyulan bir konu olduğunu ifade etmişlerdir.

\section{KÜRTÇE'DEN TÜRKÇE'YE ÇEVRILEN İFADE ÖRNEKLERİ}

Yakın coğrafyalarda yaşayan insan toplulukları fiziksel ve ruhsal ihtiyaçlarından dolayı bir arada bulunma ve yaşama gereksinimlerinden dolayı zorunlu olarak iletişim halinde bulunmuşlardır. İnsanlar arasındaki bu iletişimler sonucunda diller de birbiri ile iletişime geçmiştir. Dolayısıyla sözlü ve yazılı iletişim beraberinde diller arasında alışverişi de ortaya çıkarmıştır. Birbiri ile ilişki içinde bulunan diller doğal olarak birbirlerini etkilemişlerdir (Nalbant, 2009: 1607). 
Diller arasındaki bu ilişkiler sonucunda, bir dilden diğerine çevrilen ifadeler bazen dilin yapısına uymayabilmektedir. Alkaya (2007: 44), Doğan Aksan'ın dil ilişkileri içinde "tam çevirme sözcükler" diye adlandırdığı anlam aktarmaları/kavram tercümeleri, yabancı bir dildeki kelimelerin her üyesinin, aslına uygun olarak alıcı dildeki karşılıklarıyla çevrilmesi sonucunda ortaya çıktığını ifade etmiştir. "Meselâ, Türkçedeki "yüz suyu dökmek" deyimi Farsçadaki "ab-1 ruy rihten" deyiminin birebir aktarılmasından doğmuştur. Yine "ölü mevsim" Fransızca "morte saison"dan; kapak kızı (cover girl), kurbağa adam (frogman), yuvarlak masa toplantısı (round table meeting) gibi ifadeler ise İngilizceden Türkçeye birebir aktarılan kavram tercümeleridir." (Alkaya, 2007: 44). Bu ve buna benzer ifadeler ile bu çalışmada örnek vereceğimiz ifadeler kaynak dildeki ifadelerin diğer dile doğrudan çevrilmesi ile ortaya çıkmıştır. Bu gibi ifadeler kullanıldığında dilin mantığına, yapısına ters düşebilmektedir. Fakat özellikle çok kullanılmasından dolayı bazı ifadelerin normal kabul edildiği, yadırganmadığı da söylenebilir.

Ana dili Kürtçe olup sonradan Türkçeyi öğrenen kişilerin duygu ve düşüncelerini aktarırken farklı nedenlerle ana dildeki bazı ifadeleri ikinci bir dile aynen çevirerek kendini ifade etmesi ile Türkçe dil mantığına uymayan ifadeler ortaya çıkabilmektedir. Aşağıda bu şekilde ortaya çıkmış ifade örnekleri verilmiştir.

Kendi: Kürtçede Xwe olarak kullanılan ifadenin birebir tercümesi yapılarak kullanılması şeklinde görülür.

Kendime kitap okuyorum. (Ez ji xwe re kitêb dixwînim.)

Peşine vermek: Türkçede kovalamak kelimesinin daha çok kullanıldığ Kürtçede kullanılan ifadenin birebir çevirisinin kullanılması ile ortaya çıkmaktadır.

Okula giderken köpek peşime verdi. (Wextê ez diçûm mektebê kûçik da pey min.)

Başını yıkamak: Türkçede yıkanmak anlamında banyo yapmak veya duş almak ifadeleri kullanılmaktadır. Başını yıkamak ifadesi Kürtçedeki ifadenin çevirisidir.

Annem dün başımı yıkadı. (Duh diya min serê min ş̧̧̂şt.)

Abdest tutmak: Türkçede abdest almak olarak kullanılır.

Abdestimi tuttum camiye gidiyorum. (Min destmêj girt $\hat{u}$ diçim mizgeftê.) 
Kulağını götürmek: Kürtçedeki ifadenin bire bir çevirisi yoluyla kullanılan bir ifadedir.

Çocukların gürültüsü kulağımı götürdü. (Qîjewîja zaran guhê min bir.)

Başı gitmek: Kürtçede kullanılan ifadenin çevirisi ile söylenegelen bir ifadedir.

Başım gitti biraz susun. (Hinekî haş bin, serê min çû.)

Saç/Sakal vurmak: Türkçede saç/sakal kesmek olarak kullanılan ifade bu şekliyle Kürtçe mantıkla kullanılmıştır.

Sakalım uzadığı için bu sabah sakalımı vurdum. (Ji ber ku rihê min dirêj bib̂̂, min vê sibê rihê xwe lêda.)

Saçı/Sakalı gelmek: Türkçede saç/sakal uzaması olarak kullanılan ifade Kürtçe kullanım mantığıyla oluşturulmuş bir ifadedir.

Saçım gelmiş, berbere gideceğim. (Pora min hatiye, ez ê herim ba berber.)

Suçuna koymak: Yapmadığı bir şeyden dolayı suçlamak anlamında ve yine Kürtçedeki anlam mantığıyla kullanılan bir ifadedir.

Ben bir şey yapmadım, suçuma koymayın. (Min tu tiştî nekir, nekin sûcê min.)

Boynuna atmak: Suçlamak anlamında kullanılan ifade Kürtçedeki kullanımının çevirisiyle kullanılmaktadır.

Kardeşim odayı dă̆ıttı benim boynuma attı. (Birêlxwişka min odê belav kir lê avête stûyê min.)

Arabanın üstünde/üzerinde olmak: Anlam olarak arabayı kullanıyor olmayı karşılayan ifade Kürtçedeki ifade şekliyle kullanılmaktadır. 
Ben şimdi arabanın üstündeyim durunca sana telefon ederim. (A niha ez li ser erebê me, gava sekinim telefonî te bikim.)

Belini tutmak: Desteklemek, birinin tarafında yer almak anlamında kullanılan ifade Kürtçedeki ifadenin birebir çevirisiyle kullanılmaktadır.

Sınıfta tartışma çıkınca ben arkadaşımın belini tuttum. (Gava gengeşî derket di polê de min pişta hevalê xwe girt.)

Namazın üstünde olmak: Namazı kılıyor olmayı ifade eden kullanım Kürtçe kullanımının çevirisiyle kullanılmaktadır.

Babam namazın üstündeyken telefonu çald. (Wextê bavê min li ser nimêjê bû telefona wî lêda.)

Kâfirlerin günahı gelmek: Anlam olarak acınacak durumda olmayı karşılayan ifade Kürtçede yaygın olarak kullanılan bir ifadenin çevirisiyle kullanılmaktadır.

O kadar ağlamıştı ki kâfirlerin günahı geliyordu ona. (Ewqas giriyabû ku gunêhê kafiran pê dihat.)

Abdesti kırılmak: Türkçede abdestin bozulması olarak ifade edilen bu ifade Kürtçe mantıkla ortaya çıkmış ve Kürtçe halinin bire bir çevirisidir.

Benim abdestim kırıldı namazı sonra kılacă̆ım. (Destmêja min şikest, ez ê paşê nimêj bikim.)

Gözü çıkmak: Bir şeye, duruma veya kişiye çok acıma anlamı ifade etmek için kullanılır. Kürtçedeki 'çavê min birije' ifadesinin birebir çevirisi sonucu ortaya çıkmıştır.

Vah gözüm çıksın, ne kadar zayıflamışsın! (Weylê! Çavê min birije, tu çiqas jar bûŷ.)

Ekmek vurmak: Özellikle tandırda ekmek pişirildiğinde hamur tandırın kenarına vurularak yapılmaktadır. Bu nedenle bu eylem Kürtçede vurmak eylemi ile karşılanır. Kürtçedeki bu kullanımın aynen Türkçeye çevrilmesi ile kullanılmaktadır. Tandırda ekmek yapmak yerine kullanılan ifade günümüzde, bazı yörelerde firınlar için de kullanılmaktadır. 
Annem dün tandırl yakıp ekmek vurdu. (Duh diya min tenûrê pê xist $\hat{u}$ nan lêda.)

Hatır istemek: Türkçede 'vedalaşmak' kelimesi ile ifadesini bulan durum için kullanılır. Hatır istemek ifadesi Kürtçedeki kullanımının Türkçeye aktarılması ile ortaya çıkmıştır.

Misafirler hatır isteyip gittiler. (Mêvanan xatir ji me xwastin û çûn.)

Keyfi gelmek: Hoşa gidilen durumlar için kullanılan ifade mutlu olmak veya memnun olmak anlamlarında kullanılır. Kürtçedeki ifadenin birebir çevirisi sonucu ortaya çıkmıştır.

Onun başardı̆̆ını görünce keyfim geliyor. (Dema ku ez biserketina wîlê dibinim kêfa min jê re tê.)

Başvurmak: Ziyaret etmek anlamında kullanılan ifade yine Kürtçe anlam göz önünde bulundurularak söylenmiş ve kullanılagelen bir ifadedir.

Köydeki akrabalara başvurdum geldim. (Min serîkî li merivên me yên gund da.)

Gülmesi gelmek: Gülmeyi engelleyememek anlamında veya 'gülesi gelmek' ifadesi ile Türkçede kullanılan ifadenin Kürtçe kullanımının birebir çevirisidir.

O olay aklıma geldikçe gülmem geliyor. (Kengê ev bûyer were bîra min kena min tê.)

Allah razı olsun (kızgınlık anında): Türkçede karşılığı olmayan, Kürtçeye has bir kullanımdır. Kızgınlığı, sitemi ifade eden kullanım yine Kürtçedeki kullanımının Türkçeye aktarılması ile ortaya çıkan bir ifadedir.

Allah razı olsun, işini niye düzgün yapmıyorsun! (Xwedê'j te razî be! Tu çima kare xwe xweş nakî!)

Günah olmak: Kendisini acındırmak için kullanılan ifade Kürtçedeki ifadenin çevirisidir.

Ben günahım, bana yardımcı olun. (Ez gune me, alîkariya min bikin.) 
Sabrı çıkmak/çıkmamak: Canı sıkılmak anlamında kullanılan ifade Kürtçe ifadenin çevirisi ile kullanılmaktadır.

Onunla konuşunca sabrım çıkıyor. (Dema pê re xeber didim sebra min tê.)

Akrabası gelmek (olmak): Birisiyle akrabalık ilişkisi olmayı ifade eder. 'Akrabası sayılmak' olarak da ifade edilebilecek söz grubu Kürtçedeki kullanımının çevirisidir.

Orda oturan adam benim amcam geliyor. (Ew merivê ku li wir rûniştiye apê min tê.)

\section{SONUÇ}

Yukarıda Türkçe ve Kürtçe örnekler ve açıklamalarla da ifade edilmeye çalışıldığı gibi bu kullanımlar ikidilliliğin bir sonucu olarak ortaya çıkmaktadır. İkidilli bireylerde bir dilin diğerine göre daha baskın olduğu görülmektedir. Bu durum sonucunda bireyler hangi dilde kendilerini daha rahat ifade edebiliyorlarsa o dil ile iletişim kuruyorlar. Bazı durumlarda kendilerini daha rahat ifade ettikleri dille değil ikinci dille iletişim kurmaları gerekebilmektedir. İşte bu zamanlarda bireyler, hâkim olduğu dille düşünüp diğer dille kendini ifade etmek zorunda kalmaktadırlar. Böylece birebir çeviri yapar, hâkim olduğu dil mantığı ile konuşur. Bunun sonucunda yukarıda örneklerle belirttiğimiz ifadeler ortaya çıkar.

Günümüzde hiç Kürtçe bilmediği halde veya Kürtçeye çok hâkim olmadığı halde yine bu ifadeleri kullananların sayısı oldukça fazladır. Bunun sebebi de bu ifadelerin toplumda çok kullanılıyor olması ve bölgesel de olsa dile yerleşmesi olarak görülebilir. Böylece Kürtçede olan ve Kürtçe anlamı düşünülerek Türkçeye çevrilip kullanılan bu ifadeler garipsenmiyor ve sürekli kullanılması ile dile yerleşmiş oluyor.

Sonuç olarak iki dilli bireylerin eğitim öğretim hayatlarında, iş ve sosyal hayatlarında kendilerini daha doğru ve rahat ifade edebilmeleri için kullandıkları iki dilin dil yapısını, kurallarını iyi bilmeleri gerekmektedir. Aksi durumda bu çalışmamızda değindiğimiz gibi bir dilden diğerine birebir çeviri yapılarak ifadeler yanlış anlamaya/anlaşılmaya sebep olacak şekilde kullanılabilmektedir. Kişilerin birinci dilden ikinci dile aktardıkları bu gibi ifadelerin, kullanan kişi tarafından fark edilmesi ve dil yapısına aykırı ise düzeltilmesi eğitim öğretim ortamlarında verilen dil dersleri aracılığıyla yapılabileceği düşünülmektedir.

\section{KAYNAKÇA}

Aksan, Doğan (1979). Her Yönüyle Dil Ana Çizgileriyle Dilbilim, Cilt I-II-III, TDK Yayınları, Ankara.

Aktaş, Şerif ve Gündüz, Osman (2002). Yazılı ve Sözlü Anlatım, Akçağ Yayınları, Ankara 
Alkaya, Ercan (2007). İki Dillilik ve Rusçadan Tatar Türkçesine Geçen Kavram Tercümeleri, Turkish Studies / Türkoloji Araştırmaları, Sayı 2/2.

Alpöge, Gülçin, (2014). Çift Dilli Çocukların Dil Gelişimi, http://www.turkophone.net/wpcontent/uploads/2014/03/Alpoge.pdf (erişim tarihi: 21.06.2016)

Arat, R.Rahmeti (1966). Türk Dili İçin I (Türk Basınında Türk Dili ile İlgili Çıkmış Makaleler), Türk Kültürünü Araştırma Enstitüsü Yayınları: 25, Ankara.

Aydın, İ.Seçkin (2013). İli Dilli Türk Öğrencilerin Yazılı Anlatım Becerilerine Yönelik Bir Durum Çalışması, Turkish Studies International Periodical For the Languages, Literature and History of Turkish or Turkic Volume 8/9 Summer, s.657-670, Ankara

Boeschoten, Hendrik (1998). İki Dilli Ortamlarda Kavram Karmaşası, Doğan Aksan Armağanı, DTCF Yayınları: 366, Ankara.

Büyük Sözlük Renkli, Resimli, Ansiklopedik, (tarihsiz). Arkın Kitabevi, Cilt: 1-2, İstanbul. Celadet Ali Bedir Han \& Roger Lescot (2004). Kürtçe Gramer, Avesta Yayınları, İstanbul.

Demiray, Kemal, (1988). Temel Türkçe Sözlük, İnkılâp Kitabevi, 4. Baskı, İstanbul.

Derince, Mehmet Şerif, (2012). Anadili Temelli Çokdilli Eğitim: Nasıll, Eğitim Bilim Toplum Dergisi, Cilt: 10, Say1: 37, s.143-151.

Derince, Mehmet Şerif, (2012). Anadili Temelli Çokdilli ve Çokdiyalektli Dinamik Eğitim: Kürt Öğrencilerin Eğitiminde Kullanılabilecek Modeller, DİSA Yayınları, Diyarbakır.

Ergin, Muharrem (2000). Edebiyat ve Eğitim Fakültelerinin Türk Dili ve Edebiyatı Bölümleri İçin Türk Dil Bilgisi, Bayrak Yayıncılık, İstanbul.

Îzolî, D. (2013). Ferhenga Kurdî-Tirkî Tirkî-Kurdî, Weşanên Deng, ç. 7., Stenbol.

Karaağaç, Günay, (2011). Bireysel İkidillilik ve Toplumsal İkidillilik, Türk Dili Dergisi, s.222-228.

MEB Komisyon, (Tarihsiz). Hoş Geldin Öğretmenim, Milli Eğitim Bakanlığı, Ankara.

Nalbant, Mehmet Vefa (2009). Çok Dillilik ve Taşıyıcı Dil Kavramları Bağlamında Siirt Merkez Ağzı ve Bazı Türkçe Türkçe Sözcüklerin Durumu, Turkish Studies International Periodical For the Languages, Literature and History of Turkish or Turkic, Volume 4/3, Spring, s. 1606-1621, Ankara.

Prazig Walter (2003). "Dil Denen Mucize”, TDK Yayınları, Ankara. (Çev. Prof. Dr. Vural ÜLKÜ)

TDK, (1998). Türkçe Sözlük, Türk Dil Kurumu Yayınları, 9. Baskı, Ankara.

Tekin, Talat (1994). “Türkoloji Eleştirileri”, Doruk Yayınları, Ankara.

Temel, Z.Fulya, Şimşek Bekir, Hatice (2005). Erken Çocukluk Döneminde İki Dillilik, Türk Dili Dergisi, Sayı 637, s.65-72. Ankara. 
Türkel, Ali, Savaş, Behsat, Savaşçı, H.Sebile, (2014). Anadili Türkçe ve Kürtçe Olan 4. Sınıf Öğrencilerinin Yazmaya Karşı Tutumlarının Karşılaştırılması, Turkish Studies - International Periodical For The Languages, Literature and History of Turkish or Turkic S. 9/9 Summer, s. 